\title{
Study on radio frequency reactive sputtering deposition of silicon nitride thin films
}

F. C. Stedile, I. J. R. Baumvol, W. H. Schreiner, and F. L. Freire

Citation: Journal of Vacuum Science \& Technology A 10, 462 (1992); doi: 10.1116/1.578172

View online: https://doi.org/10.1116/1.578172

View Table of Contents: https://avs.scitation.org/toc/jva/10/3

Published by the American Vacuum Society

\section{ARTICLES YOU MAY BE INTERESTED IN}

Microstructure and properties of silicon nitride thin films deposited by reactive bias magnetron sputtering Journal of Applied Physics 83, 5831 (1998); https://doi.org/10.1063/1.367440

Mechanical properties of sputtered silicon nitride thin films

Journal of Applied Physics 94, 7868 (2003); https://doi.org/10.1063/1.1626799

Refractive index control of silicon nitride films prepared by radio-frequency reactive sputtering Journal of Vacuum Science \& Technology A 20, 2137 (2002); https://doi.org/10.1116/1.1513637

$\mathrm{SiN}_{\mathrm{X}}$ coatings deposited by reactive high power impulse magnetron sputtering: Process parameters influencing the residual coating stress

Journal of Applied Physics 121, 171904 (2017); https://doi.org/10.1063/1.4977812

Review Article: Tracing the recorded history of thin-film sputter deposition: From the 1800s to 2017 Journal of Vacuum Science \& Technology A 35, 05 C204 (2017); https://doi.org/10.1116/1.4998940

Al-doped zinc oxide films deposited by simultaneous if and dc excitation of a magnetron plasma: Relationships between plasma parameters and structural and electrical film properties

Journal of Applied Physics 83, 1087 (1998); https://doi.org/10.1063/1.366798

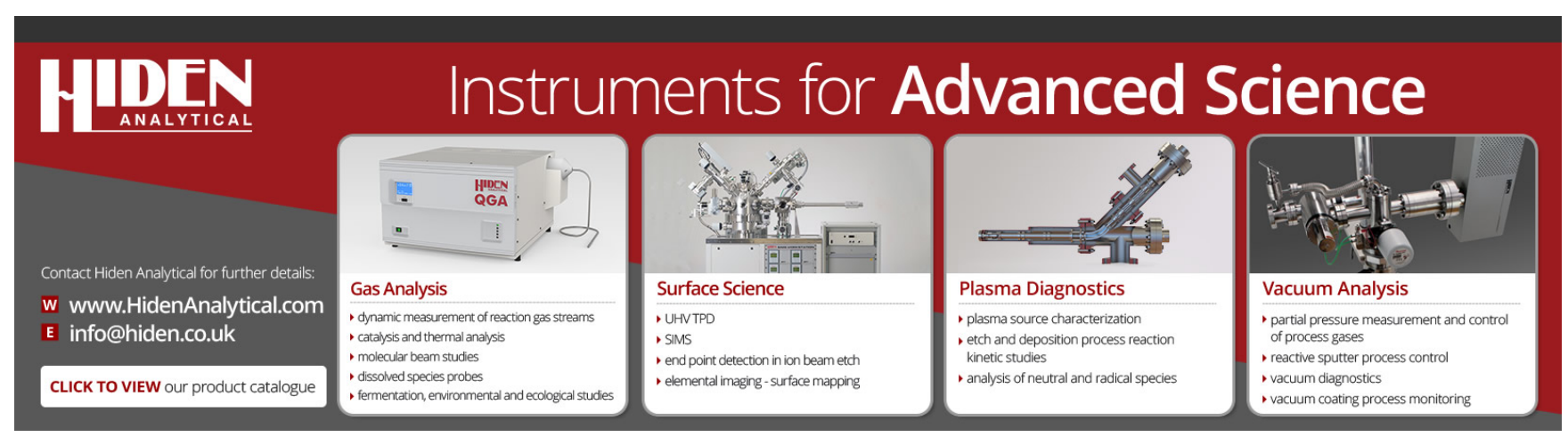




\title{
Study on radio frequency reactive sputtering deposition of silicon nitride thin films
}

\author{
F. C. Stedile \\ Instituto de Quîmica, Universidade Federal do Rio Grande do Sul, 91500-Porto Alegre-RS, Brasil \\ 1. J. R. Baumvol and W. H. Schreiner \\ Instituto de Fîsica, Universidade Federal do Rio Grande do Sul, 91500-Porto Alegre-RS, Brasil \\ F. L. Freire Jr. \\ Departamento de Fisica, Pontificia Universidade Católica do Rio de Janeiro, 22452-Rio de Janeiro-RJ, \\ Brasil
}

(Received 9 May 1991; accepted 4 January 1992)

\begin{abstract}
A rf magnetron sputtering apparatus operating at constant gas pressure was used to deposit silicon nitride thin films in an $\mathrm{Ar}-\mathrm{N}_{2}$ plasma. The nitrogen partial pressure, incident rf power, and the deposition time were varied to obtain various sets of films. In analyzing the stoichiometry and thickness of the silicon nitride films by Rutherford backscattering spectroscopy, several correlations among deposition parameters and film characteristics could be found. The results can be discussed by adapting a reactive sputtering theoretical model to the present conditions. An alternative method to grow films with the same stoichiometry but under different deposition rates was tested.
\end{abstract}

\section{INTRODUCTION}

Silicon nitride films have been playing an important role in the fabrication of semiconductor devices. Their applications range from diffusion barriers and interlevel insulation to final passivation.

The former standard method used to deposit silicon nitride films was chemical vapor deposition (CVD), where a reaction between gaseous reactants takes place in the presence of a thermal source. The CVD method was followed by the plasma-enhanced CVD technique, where the gaseous reactants are induced to react by a glow discharge. The advantages of these techniques, when compared to reactive sputtering, are the sometimes higher deposition rates achieved together with a better step coverage due to the higher pressures inside the chamber. On the other hand, the disadvantage of CVD and reactive plasma techniques is that usually the source gases are hydrogenated, causing a high hydrogen concentration in the films. This contamination with hydrogen induces some problems, such as the electrical passivation of the dopants of silicon and the shifting of the threshold voltage of a metal-oxidesemiconductor field-effect transistor (MOSFET) due to hot-electron trappings in the gate oxide when the MOSFET is encapsulated with hydrogenated silicon nitride. ${ }^{1}$ This is not the case with reactive sputtered films, since one will mostly have $\mathrm{N}_{2}$ and Ar in the chamber. The advantage of a magnetron in this last system is that it provides a more efficient ionization of the plasma gas, allowing one to lower the working pressure and obtaining, in most cases, a cleaner ambient, and also to lower the substrate temperature, since the electron bombardment of the substrates is very much reduced.

The literature on reactive sputter deposition of silicon nitride is rather sparse. The majority of the papers on silicon nitride deal with CVD and plasma-assisted CVD deposition methods and their inherent contamination with hy- drogen. There are papers that focus on the materials characteristics of silicon nitride thin films deposited by reactive sputtering, like electronic structure, magnetic properties, breakdown voltage, and leakage current of microelectronic devices, but not on the characteristics and properties of the deposition process itself. In spite of this, some comparisons could be made between the present findings and some articles of the literature as discussed below.

The present work was mainly motivated by the articles on reactive sputtering of nitride films of Berg et $a l^{2-8}$ In the experimental part of their work they noticed, as other authors did before, ${ }^{9-11}$ a drop in deposition rate when the nitrogen partial flow is increased, as is shown in Fig. 1(a). The explanation they gave concerning this transition region abandoned the commonly accepted idea of a "critical pressure" and, instead, worked only with well-known physical properties like fiow, ion current density, sputtering yield, sticking coefficients, and others. A different approach, which also used such physical properties, was earlier presented by Affinito and Parsons ${ }^{12}$ in their study on the mechanisms of sputtering of $\mathrm{Al}$ in reactive atmospheres ( $\mathrm{Ar} / \mathrm{N}_{2}$ and $\mathrm{Ar} / \mathrm{O}_{2}$ ). In Berg's articles the drop in the deposition rate is described in a simple way where nitrogen is gettered by sputtered metallic atoms up to a certain flow, above which an incremental increase in nitrogen supply causes some nitride formation on the metal target surface. The erosion rate of the target then decreases, causing a further decrease in the gettering of nitrogen. This will increase even more the formation of nitride at the target. A runaway situation develops, resulting in a sharp transition from metallic target to a metallic-nitrided target surface. It is near this pressure region that it is possible to deposit nitride films consisting mainly of a stoichiometric compound.

Furthermore, these authors proposed a mathematical model which described the process of reactive sputtering of 

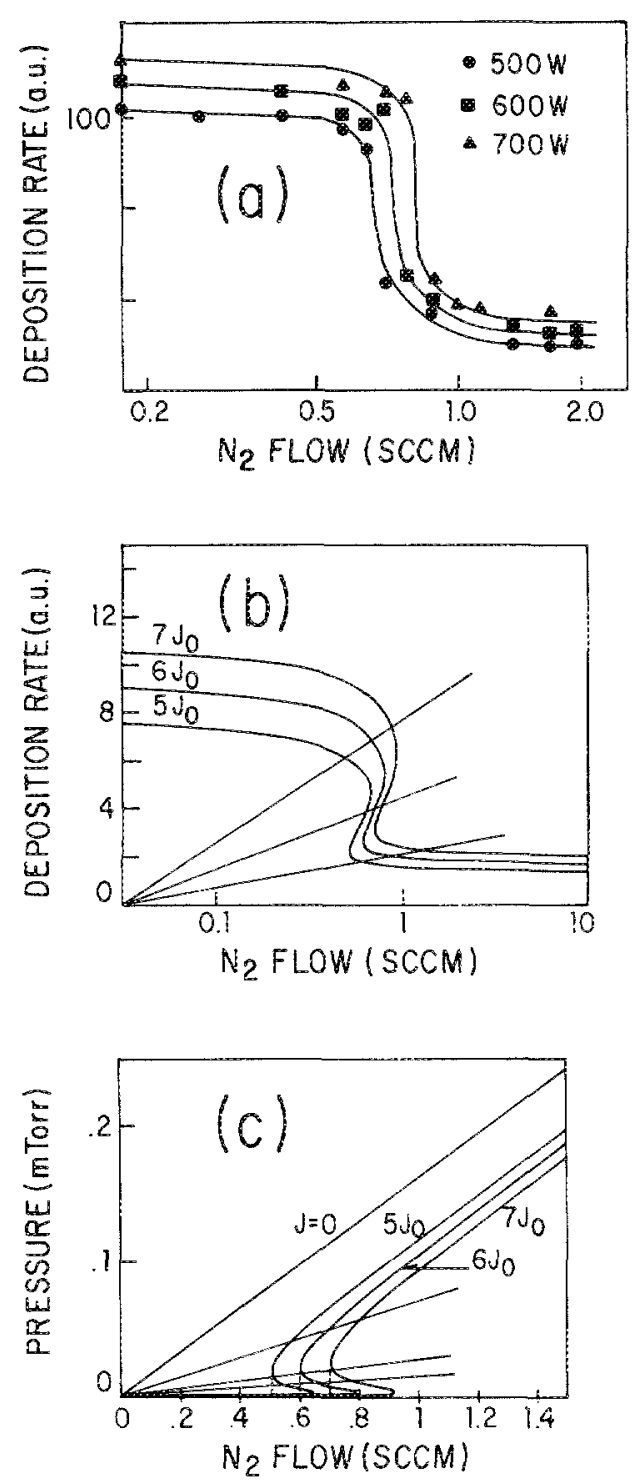

FIG. 1. From Ref. 3: (a) Experimental sputtering rate vs nitrogen mass flow for different of powers. (b) Calculaked sputtering rate vs nitrogen mass flow and (c) calculated nitrogen partial pressure us incoming nitrogen mass fow for different argon-ion current densities $\left(J_{0}\right.$ $=0.2 \mathrm{~mA} / \mathrm{cm}^{2}$ ). The straight lines intercept the curves at points corresponding to films with the same stoichiometric composition.

$T i$ in a gas mixture of argon and nitrogen. They used the model equations to make graphs of the nitrogen mass flow versus sputtering rate and of the nitrogen flow versus nitrogen pressure for a given argon-ion current density and argon flow. These graphs are reproduced in Figs. 1(b) and $1(c)$. The runaway situation gives rise to a hysteresis region [not shown in Fig. 1(a)], namely the path in which the nitrogen flow is increased is different from that when nitrogen flow is decreased. However, in a sputtering apparatus with feedback control of pressure it is possible to obtain points inside the instability region. ${ }^{7,13}$ These experimental curves, now without hysteresis, can be fitted by the theoretical model. An aspect worth mentioning is the monotonic correlation found between the argon-ion current densities, used as parameters in the model, and the incident $\mathrm{rf}$ powers, used in each set of experiments, which allowed the comparison between the experimental curves and the calculated ones. Another feature extracted from the model is that the ratios nitrogen pressure to nitrogen flow and sputtering rate to nitrogen flow are constants. This means that in the corresponding graphs (nitrogen pressure versus nitrogen flow and sputtering rate versus nitrogen flow) straight lines from the origin intercept the curves of different incident powers at points corresponding to films with the same stoichiometric composition, although obtained at different sputtering rates or pressures [Figs. 1(b) and 1(c)].

In the present work thin films of silicon nitride were deposited by if magnetron sputtering. The plasma consisted in a mixture of $\mathrm{Ar}$ and $\mathrm{N}_{2}$, where the Ar partiai pressure was kept constant. The nitrogen partial pressure as well as the incident if power were varied independently during the preparation of the samples in order to estimate the role of each parameter in the deposition process. Adapting the model of reactive sputtering discussed above to this specific case, where the total pressure was kept constant, it was possible to compare the theoretical predictions to some experimental results. Based on such comparisons a correlation between deposition rate and self-bias voltage $\left(V_{\mathrm{dc}}\right)$ was found. Another relevant point is that the ratio of sputtering rate to nitrogen pressure is also constant, indicating an alternative way to deposit isostoichiometric films with different sputtering rates.

\section{EXPERIMENTAL DETAILS}

The silicon nitride films were deposited in a Balzers BAS-450 magnetron sputtering system using the rf power supply. The equipment has a feedback mechanism to maintain the pressures of the gases ( $\mathrm{Ar}$ and $\mathrm{N}_{2}$ in our case) at a constant level. The partial pressures of Ar and $\mathrm{N}_{2}$ can be monitored by a residual gas analyzer based on a mass spectrometer. The distance between the pure Si $99.999 \%$ target $(7 \mathrm{~cm} \times 17 \mathrm{~cm})$ and the substrate is $10 \mathrm{~cm}$. The vacuum chamber is pumped by a turbomolecular pump of $1500 \mathrm{l} / \mathrm{s}$ to a base pressure lower than $5 \times 10^{-4} \mathrm{~Pa}$ and then throttled to start the gas admission. In every deposition set the chamber was pressurized with $6 \times 10^{-2} \mathrm{~Pa}$ of $\mathrm{Ar}$, which was the minimum Ar pressure that could maintain the plasma, and then $\mathbf{N}_{2}$ was admitted to reach the desired pressure. The incident powers used were 300,400 , and 500 $W$ with reflected powers nearly zero. The substrates were Si(100) and polyimide films $25 \mu \mathrm{m}$ thick. After a chemical cleaning of the substrates, we submitted the Si ones to a rf plasma etching (inside the vacuum chamber) during $7 \mathrm{~min}$ at an Ar pressure of $3 \times 10^{-1} \mathrm{~Pa}$ prior to deposition. To deposit the films, the variable parameters were the nitrogen partial pressure $\left(P_{\mathrm{N}_{2}}\right)$, the incident power, and the deposition time. During deposition we could follow the process observing the partial and total pressures and self-bias voltage $\left(V_{\mathrm{dc}}\right)$ developed at the target, and a very good degree of reproducibility run to run was found.

Thickness and composition of the silicon nitride films were analyzed by means of Rutherford backscattering 

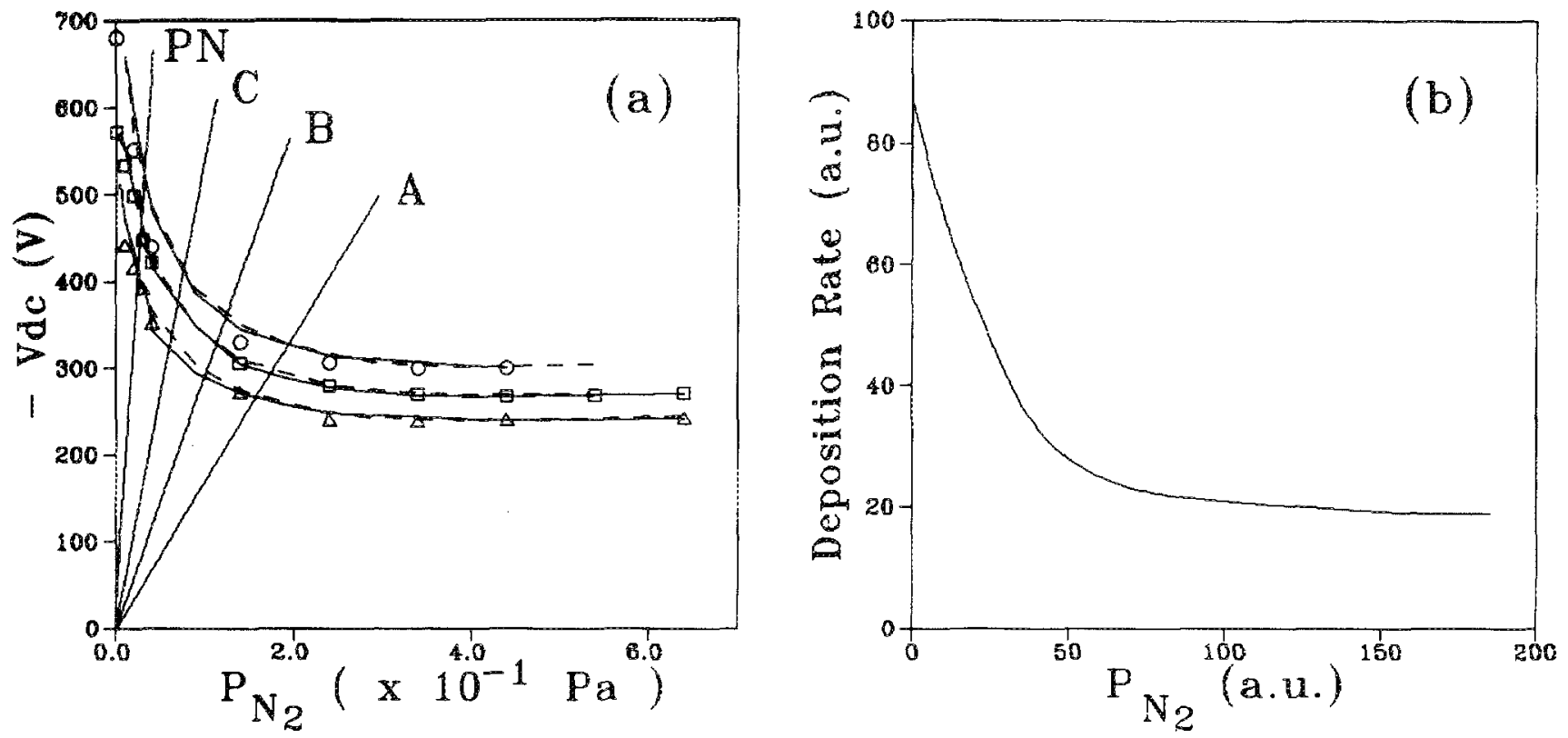

Fro. 2. (a) Experimental target self-bias voltage vs nitrogen partial pressure curves for incident powers of ( $\Delta$ ) $300 \mathrm{~W}$, (D) $400 \mathrm{~W}$, and (O) $500 \mathrm{~W}$. For a given incident power, the points represent the first increase in nitrogen partial pressure, the solid line represents the subsequent decrease in nitrogen pressure, and the dashed one when the nitrogen pressure is increased again. The straight lines intercept the curves at points corresponding to films with the same stoichiometric composition. (b) Calculated sputtering rate vs nitrogen partial pressure extracted from Berg's model. The sputtering rate and the nitrogen partial pressure are given in arbitrary units (a.u.).

spectrometry (RBS) at 0.760 and $2.000 \mathrm{MeV}$ for polyimide and $\mathrm{Si}(100)$ substrates, respectively. Details on the technique and on data treatment are presented in Ref. 14.

\section{RESULTS}

Berg $e t a l$, in their work on TiN reactive sputtering deposition, ${ }^{2-6}$ controlled the nitrogen flux $\left(F_{\mathrm{N}_{2}}\right)$ into the chamber. The dependence of the sputtering rate (S.R.) and nitrogen partial pressure $\left(P_{\mathrm{N}_{2}}\right)$ on this flux are shown in Fig. 1. In the present work we kept constant the pressures and obtained, for various incident powers, the curves of the variation of the target self-bias voltage $\left(V_{\mathrm{dc}}\right)$ with the reactive gas (nitrogen) partial pressure shown in Fig. 2(a). The dependence found here for the silicon nitride deposi-
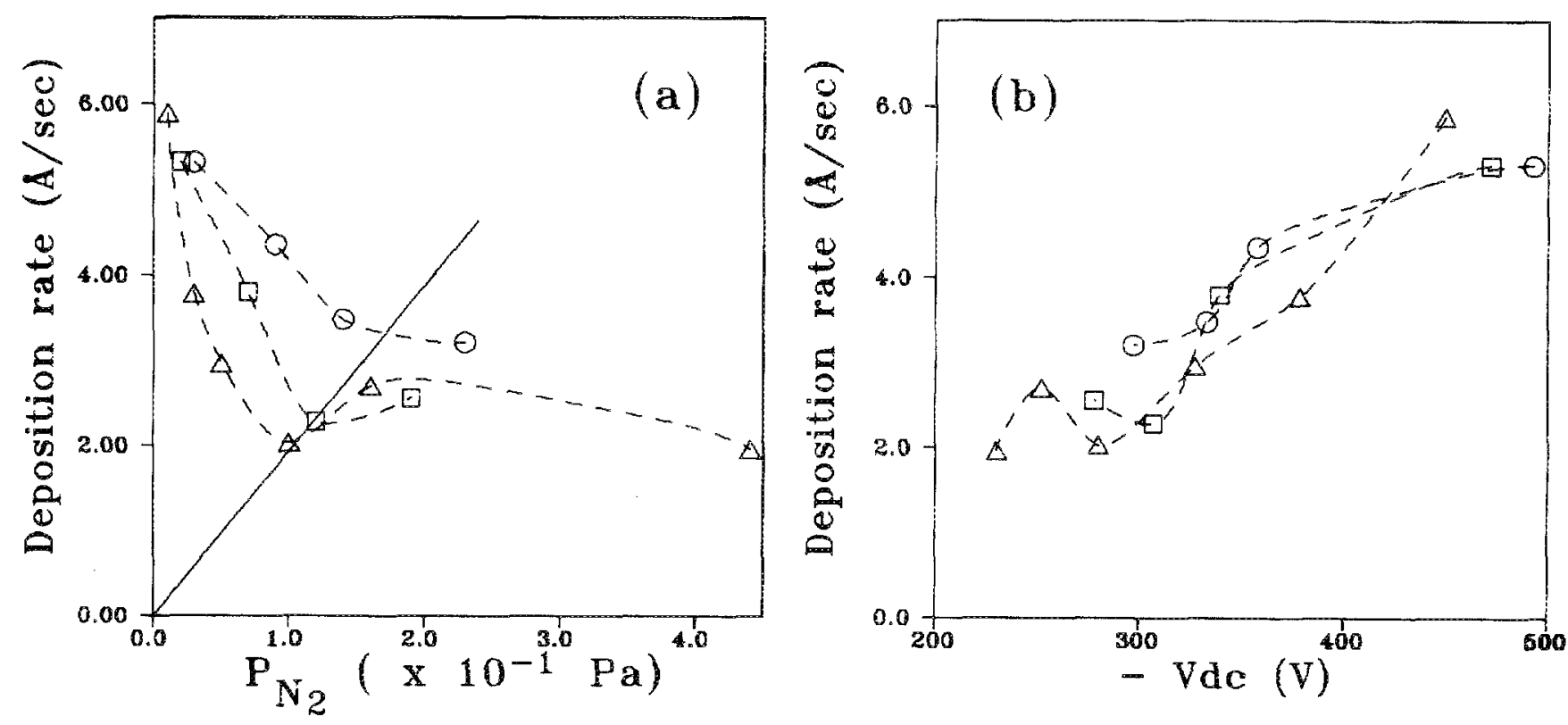

FIG. 3. (a) Experimental deposition rate vs nitrogen partial pressure for incident powers of $(\triangle) 300 \mathrm{~W}$, ( $\square$ ) $400 \mathrm{~W}$, and (O) $500 \mathrm{~W}$. The straight line intercepts the curves at points corresponding to films with the same stoichiometric composition. (b) Experimental relationship between deposition rate and target seif-bias voltage for incident powers of $(\Delta) 300 \mathrm{~W},(\square) 400 \mathrm{~W}$, and $(0) 500 \mathrm{~W}$. The dashed lines are not fittings; they are used just to guide the eyes through the experimental points. 


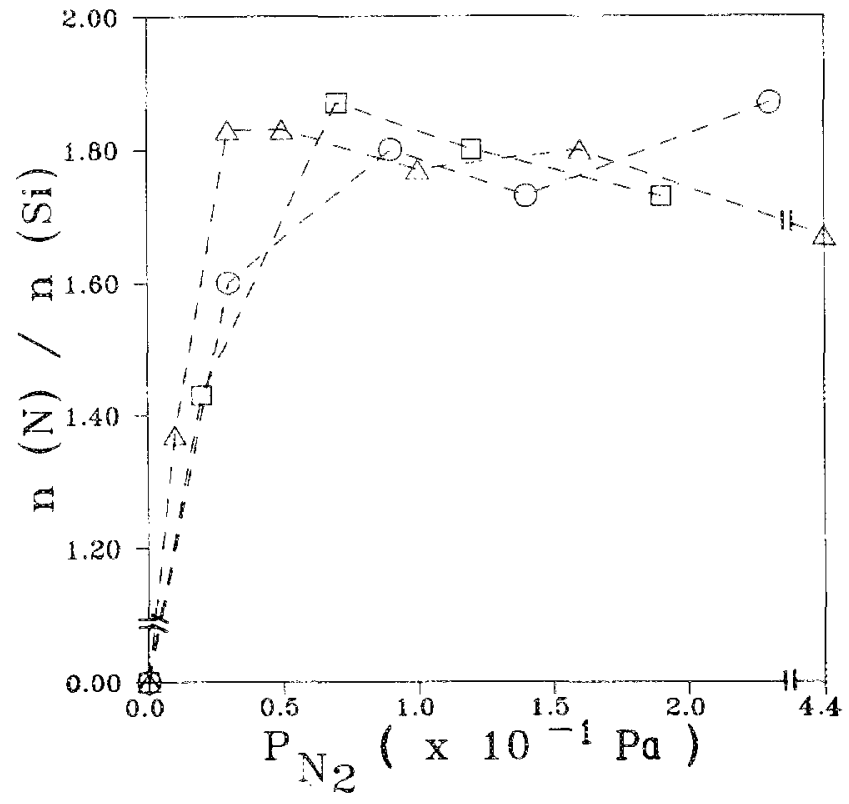

FIG. 4. Stoichiometric fraction as determined by $0.760 \mathrm{MeV}$ c $z$-particie Rutherford backscattering spectroscopy as a function of the nitrogen partial pressure for incident powers of $(\Delta) 300 \mathrm{~W},(\square) 400 \mathrm{~W}$, and (O) 500 $W$. The dashed lines are not fittings; they are used just to guide the eyes through the experimental points.

tion is similar to the one extracted from Berg's model, shown in Fig. 2(b). To draw this last curve we used points with the same flux in the plots of $P_{\mathrm{N}_{2}} \times F_{\mathrm{N}_{2}}$ and S.R. $\times F_{\mathrm{N}_{2}}$ given in Figs. 1(b) and 1(c) and plotted $P_{\mathrm{N}_{2}}$ versus the corresponding sputtering rate. As we can see

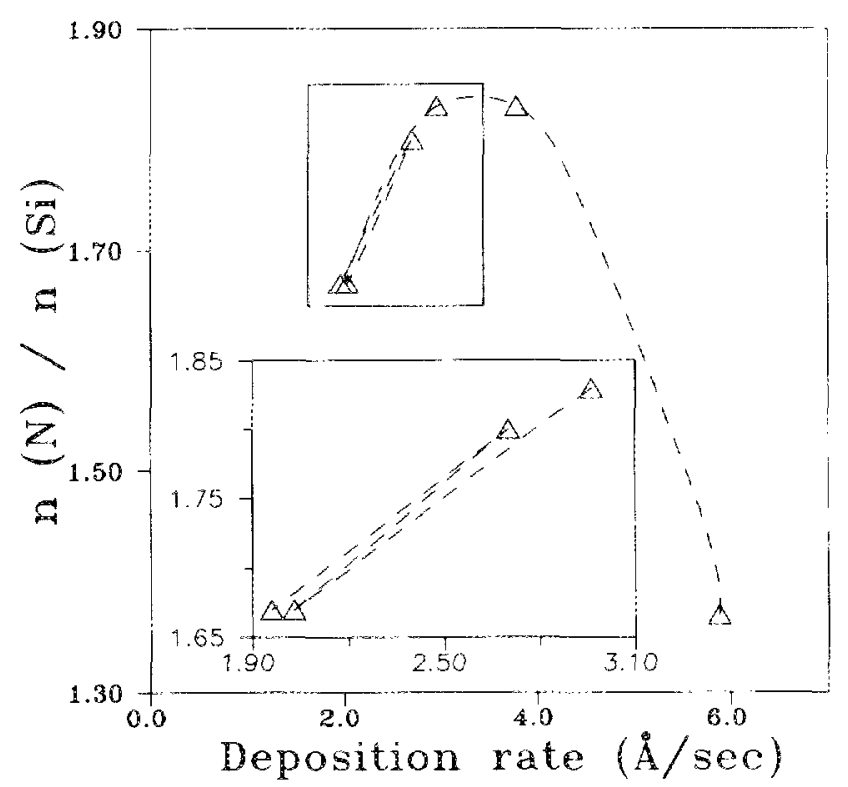

FIG. 5. Experimental relationship between stoichiometric fraction obtained from $0.760 \mathrm{MeV}$ RBS and the deposition rate for an incident power of $300 \mathrm{~W}$. The detail evidences the superposition of the points. The dashed line is inot a fitting; it is used just to guide the eyes through the experimental points. from Figs. 2(a) and 2(b) the agreement between the theoretical and experimental curves is very good.

The curves in Fig. 2(a) were obtained starting with a plasma made basically of Ar $\left(6 \times 10^{-2} \mathrm{~Pa}\right)$, letting $\mathrm{N}_{2}$ to flow slowly into the chamber and measuring $V_{\mathrm{dc}}$ at certain working pressures, until reaching a rather high pressure $\left(P_{\mathrm{N}_{2}}=6.4 \times 10^{-1} \mathrm{~Pa}\right.$ for the $300 \mathrm{~W}$ curve $)$. This is shown by dotted curves in the figure. After that, we diminished the $P_{\mathrm{N}_{2}}$ (solid lines) and again increased the nitrogen partial pressure (dashed lines). The aim was to detect (for silicon nitride and in the conditions of this work) the hysteresis loops, which have been seen by several authors ${ }^{4,13,15}$ for other compounds deposited by reactive sputtering under different process control conditions. However, in the present case they could not be seen, as also happened for TiB (Ref. 8) under other specific deposition conditions.

The similarity between Figs. 2(a) and 2(b) reveals a relationship between the sputtering rate and $V_{\mathrm{dc}}$. Based on the thickness of silicon nitride films grown during the same deposition times, we could plot the deposition rate versus $P_{\mathrm{N}_{2}}$. The results, for different incident powers, can be seen in Fig. 3(a). The resemblance with Fig. 2(b) can again be noticed. In Fig. 3(b) the relationship between the deposition rate and $V_{\mathrm{dc}}$ is shown. It is clear that the dependence is not linear.

In Figs. 2(a) and 3(a) we see that for a certain $P_{\mathrm{N}_{2}}$ the $\left|V_{\mathrm{dc}}\right|$ and the deposition rate increase as the incident power is increased, or from another point of view, to obtain a certain deposition rate or $V_{\text {ac }}$ one should increase the $P_{\mathrm{N}_{2}}$ when the power is increased.

In Fig. 4 we have the dependence of the stoichiometric fraction $n(\mathrm{~N}) / n(\mathrm{Si})$ on $P_{\mathrm{N}_{2}}$ and we can see that from 0.5 to $2.3 \times 10^{-1} \mathrm{~Pa}$ the nitride stoichiometry was nearly constant, within an error of $\pm 10 \%$, for all tested incident powers. On the other hand, at low pressures, the increase of the nitrogen content in the film with $P_{\mathrm{N}_{2}}$ is very fast.

Another interesting feature is the correlation between deposition rate and stoichiometry. In Fig. 5 we obtained this relationship for films deposited under $300 \mathrm{~W}$, where each point represents a film deposited under a certain $P_{\mathrm{N}_{2}}$. We can see that films grown under different $P_{\mathrm{N}_{2}}$ but resulting with the same stoichiometry were obtained with the same deposition rate, as is evidenced in the zoom of the figure.

Berg's model predicts that straight lines passing through the origin in S.R. $\times F_{\mathrm{N}_{2}}$ and $P_{\mathrm{N}_{2}} \times F_{\mathrm{N}_{2}}$ plots [Figs. I(b) and 1(c)] will intercept the curves obtained at different incident powers in points whose coordinates contain the parameters that will lead to isostoichiometric films. ${ }^{5}$ We tried to verify if this prediction would also describe our $V_{\mathrm{dc}}$ $\times P_{\mathrm{N}_{2}}$ and D.R. $\times P_{\mathrm{N}_{2}}$ plots of Fig. 2(a) and 3(a). In Fig. 3 (a) a straight line could be drawn passing through the origin. By analyzing the stoichiometry of such films we confirmed the expectation: they do have the same stoichiometry (admiting an error of $5 \%$ ) as one can extract from Fig. 4. In Fig. 2(a) four straight lines (A,B,C,PN) were drawn and each line originated the deposition conditions of 

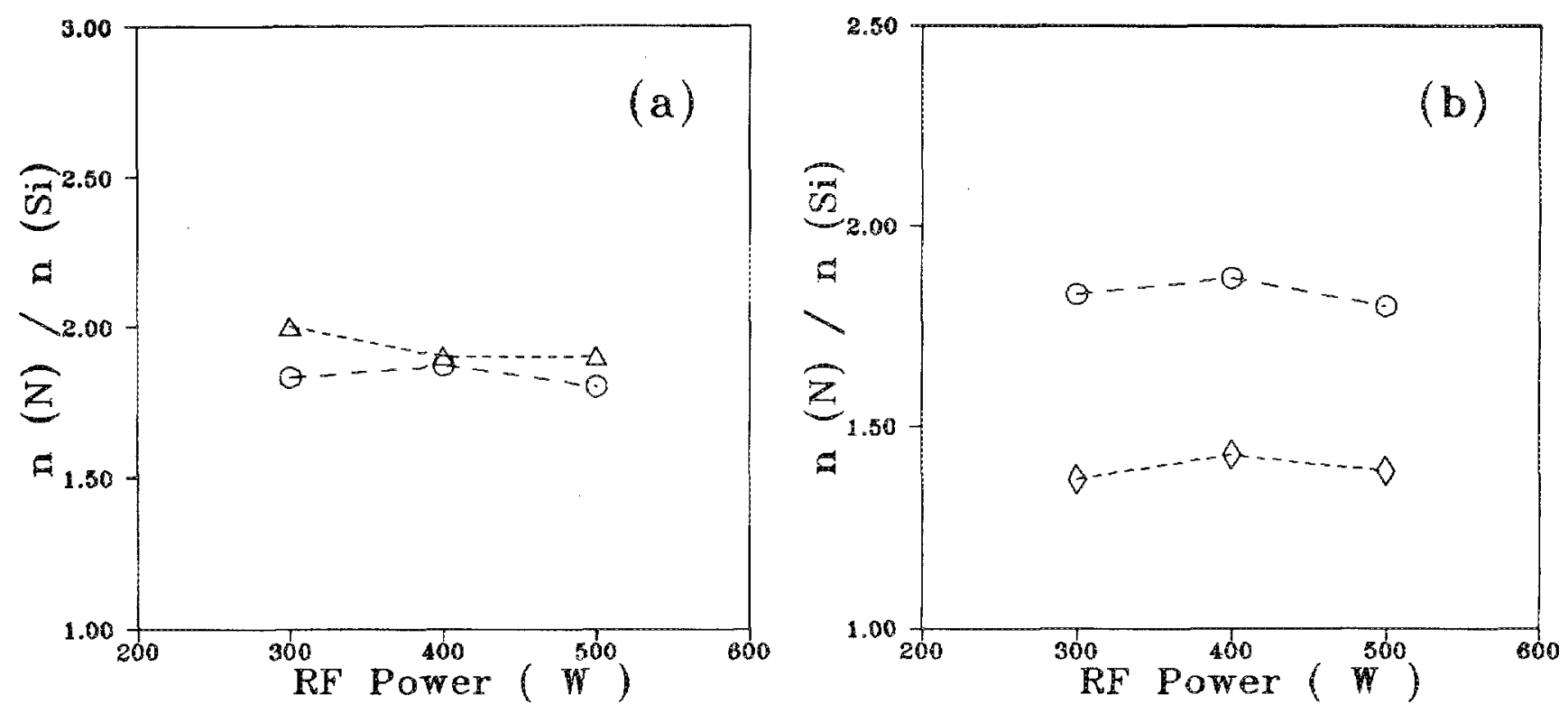

FIG. 6. (a) Stoichiometric fractions obtained: $(\Delta)$ from Rutherford backscattering spectroscopy with 2.000$) \mathrm{MeV}$ incident $\alpha$-particles and $(\mathrm{O}) 0.760$ $\mathrm{MeV}$ incident $\alpha$-particles as a function of the incident ro power for stoichiometry " $\mathrm{C}^{\text {ss }}$ films. (b) Stoichiometric fractions obtained from $0.760 \mathrm{MeV}$ $\alpha$-particle Rutherford backscattering spectroscopy vs the incident of power: $(O)$ refers to stoichiometry " $\mathrm{C}$ " and $(\diamond)$ to stoichiometry "PN." The dashed lines are not fittings; they are used just to guide the eyes through the experimental points.

three films (with incident powers of 300,400 , and $500 \mathrm{~W}$ ). In verifying the stoichiometry of these films, we concluded that the $n(\mathrm{~N}) / n(\mathrm{Si})$ ratios do remain constant, within an error of $10 \%$, for silicon nitride films deposited at different powers. In Fig. 6(a) are shown the $n(\mathrm{~N}) / n$ (Si) ratios for stoichiometry "C" as measured by RBS at $0.760 \mathrm{MeV}$ and RBS at $2.000 \mathrm{MeV}$ incident energies, revealing the good agreement attained by the techniques. The results obtained

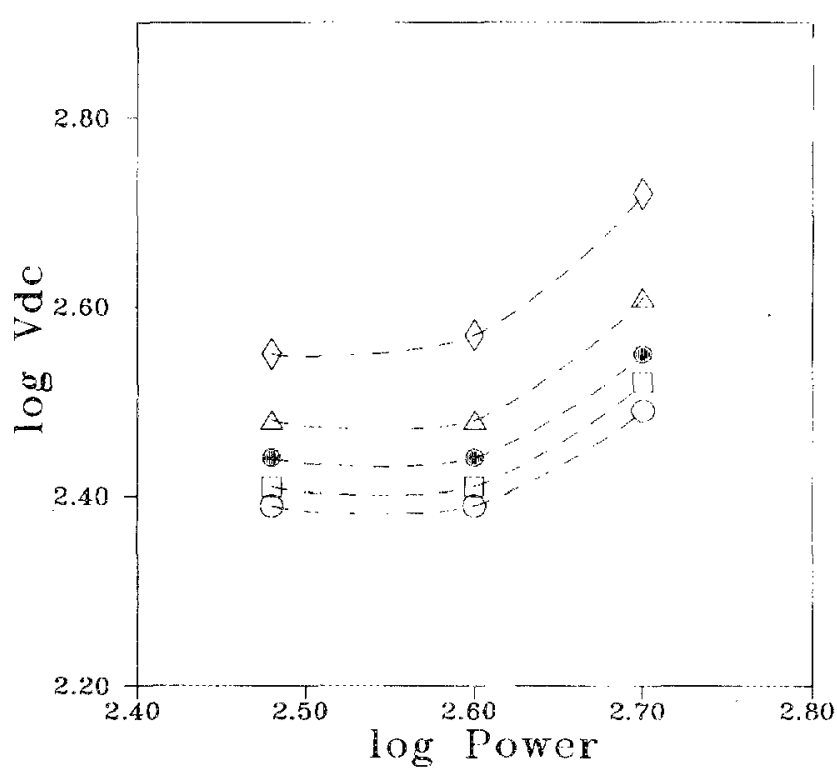

FIG. 7. $\log \times \log$ plot of the target self-bias voltage vs rf power for different total pressures: $(\diamond) 0.9 \times 10^{-1} \mathrm{~Pa}_{3}(\Delta) 1.4 \times 10^{-1} \mathrm{~Pa},(0) 1.9 \times 10^{\cdots}$ $\mathrm{Pa},(\square) 2.4 \times 10^{-1} \mathrm{~Pa}$, (O) $2.9 \times 10^{-1} \mathrm{~Pa}$. The dashed lines are not fittings; they are used just to guide the eyes through the experimental points. by RBS analysis at an incidence energy of $0.760 \mathrm{MeV}$ for all the tested stoichiometries demonstrate that the films with expected stoichiometries $\mathrm{A}, \mathrm{B}$, and $\mathrm{C}$ have very similar $n(\mathrm{~N}) / n(\mathrm{Si})$ ratios, while the ones of PN stoichiometry have a nitrogen content much lower than the others. In Fig. $6(b)$ is shown the difference in nitrogen content of the films with stoichiometries " $\mathrm{C}$ " and "PN."

\section{DISCUSSION}

Serikawa and Okamoto ${ }^{16}$ discussed the deposition of silicon nitride films in an Ar- $\mathrm{N}_{2}$ plasma, working in the very low nitrogen partial pressures side $\left(3 \times 10^{-2} \mathrm{~Pa}<P_{\mathrm{N}_{2}}\right.$ $\left.<3 \times 10^{-1} P a\right)$. The results they obtained for the deposition rate versus nitrogen partial pressure and film composition $n(\mathbb{N}) / n(\mathrm{Si})$ versus nitrogen partial pressure resemble the present results with some discrepancies when analyzed in a quantitative way. The discrepancies between these two experiments are due to differences in the $\mathrm{rf}$ power, rotation of the substrate holder, substrate temperature, total and partial pressures, target size, and target-tosubstrate distance.

In the high nitrogen partial pressures side (up to $P_{\mathrm{N}_{2}}=8 \times 10^{-1} \mathrm{~Pa}$ ) one finds the work by Mogab and Lugujo ${ }^{17}$ that deposited silicon nitride films performing the sputtering depositions in a pure $\mathrm{N}_{2}$ plasma. The films they grew were always hyperstoichiometric $[n(\mathrm{~N}) / n(\mathrm{Si})$ $>1.33$ ] similar to those of the present work. Nevertheless, they found a linear dependence between the $\log \left|V_{\mathrm{dc}}\right|$ and $\log P_{\mathrm{N}_{2}}$ keeping the if power constant, while here, using smailer total pressures as well as mixtures of $\mathrm{N}_{2}$ and $\mathrm{Ar}$, we found a nonlinear dependence. Mogab and Lugujo also obtained a linear dependence between $\log \left|V_{\mathrm{de}}\right|$ and $\log$ rf power when the partial pressure of nitrogen is kept con- 
stant, in contrast with the results of the present work shown in Fig. 7, where a clearly nonlinear dependence is observed.

The basic guidelines and findings of the model on reactive sputtering developed by Berg and collaborators were already presented in a previous section. A rather good agreement between that theory and our experimental data was verified. Furthermore, the present results can also be compared with the experimental data by Berg et $a l$. as, for example, those reported in Ref. 2 where the deposition of $\mathrm{ZrN}$ by reactive sputtering was studied experimentally. Once again there is a very good qualitative resemblance between the plots in Ref. 2 of the stoichiometric fraction $n(\mathrm{~N}) / n(\mathrm{Zr})$ versus nitrogen partial pressure and of the deposition rate versus nitrogen partial pressure and the plots of this work displayed in the previous section. A more quantitative comparison, however, is difficult to be made due to the differences in configuration of the sputtering equipments used in the two works, the different inherent chemical and physical characteristics of silicon nitride and zirconium nitride, and also because of the different nitrogen pressures used in the two works.

Some final remarks have still to be made concerning the discussion of the results in the light of Berg's model. The latter is strictly valid only for a steady-state situation and for the low nitrogen pressures range, since it does not take into account the sputtering caused by nitrogen ions and other related effects. ${ }^{4}$ Concerning the present work, the condition of low nitrogen partial pressure is not assured in many of the deposition conditions used (the $P_{\text {Ar }}$ was always $0.6 \times 10^{-1} \mathrm{~Pa}$ while the $P_{\mathrm{N}_{2}}$ ranged from 0.3 to $7 \times 10^{-1} \mathrm{~Pa}$ ). Moreover, in the deposition conditions that originated the present films the fact that there might not have been enough time to allow the system to reach a steady-state situation, as well as the presence of the feedback mechanism for $P_{\mathrm{N}_{2}}$, may be responsible for some differences observed when comparing the results.

\section{CONCLUSIONS}

Thin films of silicon nitride were deposited by $\mathrm{rf}$ reactive sputtering in $\mathrm{Ar}-\mathrm{N}_{2}$ plasmas at various nitrogen partial pressures. During each deposition set the pressure was kept constant as well as the incident power. The infuence of the nitrogen partial pressure on the target self-bias voltage, on the deposition rate, and on the film stoichiometry was described. Another observed aspect was the univocal depen- dence between the stoichiometric fraction $n(\mathrm{~N}) / n(\mathrm{Si})$ and the deposition rate of the films.

The stoichiometry of films deposited under constant gas pressure was determined experimentally by Rutherford backscattering spectroscopy. Berg's theoretical model on reactive sputtering states that isostoichiometric silicon nitride films can be deposited under different nitrogen partial pressure and if power conditions. Both analytical techniques confirmed the expected constancy of the stoichiometric fractions $n(\mathrm{~N}) / n(\mathrm{Si})$ within the experimental errors.

As a final remark, it must be emphasized that with the present equipment conditions silicon nitride films of a specific stoichiometry can be deposited under different chosen conditions of nitrogen partial pressure or incident power. The extension of this approach to deposit other compound flims by reactive sputtering is in progress.

\section{ACKNOWLEDGMENT}

This work was supported in part by Conselho Nacional de Desenvolvimento Científico e Tecnológico (CNPq, Brasil).

R. C. Sun, J. T. Clements, and I. T. Nelson, I8th Annual Proceedings on Reliability Physics, Las Vegas, 1980 (IEEE, New York, 1980), p. 244.

${ }^{2}$ H.O. Blom, S. Berg, and T. Larsson, Thin Solid Films 130, 307 (1985).

${ }^{3}$ S. Berg, T. Larsson, and H.O. Blom, I. Vac. Sci. Technol. A 4, 594 (1986).

${ }^{4}$ S. Berg, H-O. Blom, T. Larsson, and C. Bender, J. Vac. Sci. Technol. A 5, 202 (1987).

${ }^{5}$ S. Berg. T. Larsson, C. Nender, and H-O. Blom, J. Appl. Phys. 63,887 (1988).

${ }^{6}$ T. Larsson, H-O. Blom, C. Nender, and S. Berg, J. Vac. Sci. Technol. A 6,1832 (1988).

'S. Berg, H-O. Blon, M. Moradi, C. Nender, and T. Larsson, J. Vac. Sci. Technol. A 7, 1225 (1989).

${ }^{8}$ T. Larsson, H-O. Blom, S. Berg, and M. Östling, Thin Solid Films 172, 133 (1989).

${ }^{9}$ F. Shinoki and A. Itoh, J. Appl. Phys. 46, 3381 (1975).

${ }^{10}$ S. Maniv and W. D. Westwood, J. Appl. Phys. 51, 718 (1980).

${ }^{11} G$. Lempérière, Le Vide Les Couches Minces 229, 549 (1985).

${ }^{12}$ J. Affinito and R. R. Parsons, J. Vac. Sci. Technol. A 2, 1275 (1984).

${ }^{13}$ R. McMahon, J. Affinito, and R. R. Parsons, J. Vac. Sci. Technol. A $20,376(1982)$.

${ }^{14}$ F. C. Stedile, C. V. Barros Leite, W. H. Schreiner, and I. J. R. Baumvol, Thin Solid Films 190, 139 (1990). See also F. C. Stedile, F. L. Freire, Jr, I. J. R. Baumvol, and W. H. Schreiner, Nucl. Instrum. Methods B (to be published)

${ }^{15}$ S. Kadlec, I. Musil, and H. Vyskocil, J. Phys. D 19, L187 (1986).

${ }^{16} \mathrm{~T}$. Serikawa and A. Okamoto, J. Electrochem. Soc. 131, 2928 (1984).

${ }^{17}$ C. J. Mogah and E. Lugujio, J. Appl. Phys. 47, 1302 (1976). 